\title{
Electrochemical Behavior of Simetryn Herbicide at Water|1,2-Dichloroethane Interface
}

\author{
Miguel Velázquez-Manzanares, ${ }^{1, z}$ Humberto García Martínez, ${ }^{1}$ Lidia Mabel Yudi, ${ }^{2}$ \\ Judith Amador-Hernández, ${ }^{1}$ Iliana M. de la Garza Rodríguez, \\ and Edith M. Colunga Urbina ${ }^{1}$
}

${ }^{1}$ Facultad de Ciencias Químicas, Universidad Autónoma de Coahuila, 25280 Saltillo, Coahuila, México

${ }^{2}$ INFIQC, Departamento de Fisicoquímica, Facultad de Ciencias Químicas, Universidad Nacional de Córdoba,

Ciudad Universitaria, 5000 Córdoba, Argentina

\begin{abstract}
Herein, the electrochemical behavior of the simetryn herbicide at the water|1,2-dichloroethane interface was investigated by cyclic voltammetry and electrochemical impedance spectroscopy. Parameters such as transfer Gibbs energy, ionic partition coefficient, and the apparent rate constants across the interface were evaluated. According to the results, the ionic form of this herbicide is highly hydrophobic because $\Delta_{o}^{w} G_{S I M H^{+}}^{0^{\prime} w \rightarrow o}$ is $3.57 \mathrm{~kJ} \mathrm{~mol}^{-1}$ and $\log P_{S I M H^{+}}^{0^{\prime}}$ is -0.622 . In addition, the ionic partition diagram for this compound shows dual behavior as a function of $\mathrm{pH}$ : when $\mathrm{pH}<\mathrm{pKa}$, simetryn is transferred as a whole protonated molecule across the interface; whereas, when $\mathrm{pH}>\mathrm{pKa}$, simetryn serves as a mobile proton carrier across the interface. The present study offers some important insights that help in understanding the partitioning and kinetic processes of environmentally important molecules across biological membranes.

(C) The Author(s) 2019. Published by ECS. This is an open access article distributed under the terms of the Creative Commons Attribution 4.0 License (CC BY, http://creativecommons.org/licenses/by/4.0/), which permits unrestricted reuse of the work in any medium, provided the original work is properly cited. [DOI: 10.1149/2.0481908jes]

(cc) BY
\end{abstract}

Manuscript submitted October 31, 2018; revised manuscript received April 4, 2019. Published April 26, 2019.

Herbicides are commonly employed in agriculture to control unwanted plants and improve food production. The increase in population has led to an increase in food demand, thereby necessitating increased production of food crops. Therefore, farmers have used a large amount of pesticides, thus generating the problem of soil and water contamination. ${ }^{1}$

Because the process of partitioning of organic compounds across biological membranes is complicated, researchers have focused on the development of a simpler model to represent the transport of ions and molecules across hydrophobic barriers. The partition equilibrium across the water|oil and water|lipid membranes, gives an indication of the affinity of the chemical compound for the membrane structure of biological cells.

The herbicide simetryn (SIM) belongs to the triazine family, which are photosynthetic inhibitors. Their physiochemical characteristics include low solubility in water, low photodecomposition rates, and low volatility. ${ }^{2}$ The mobility of these herbicides in soil depends largely on their chemical properties, such as water solubility, and the ability to adsorb onto soil.

The interface of two immiscible electrolyte solutions (ITIES) has been studied to understand the transport of cations and organic molecules between two liquids of different polarity. The ITIES can mimic the water|lipid membrane of biological cells, because the interface can be electrically polarized through an external source. The interface between two immiscible liquids behaves as an electrode immersed in an electrolyte solution (M|S). Thus, the ITIES can be polarized in the same manner as the $\mathrm{M} \mid \mathrm{S}$ interface. ${ }^{3}$ Therefore, the ITIES can be useful to understand the transfer of SIM in a water|organic solvent system.

The ITIES has been used for the analysis of biological samples using micro-ITIES, ${ }^{4}$ and for the detection of timolol ${ }^{5}$ and myoglobin. ${ }^{6}$ Kinetic studies on micropipettes having internal tip diameters ranging from 5 to $38 \mu \mathrm{m}$ have also been carried out. ${ }^{7}$ Stripping analysis at micro-interface arrays has been employed for heavy metal detection in environmental samples. ${ }^{8}$

Dopamine detection at the ITIES using a highly hydrophobic ionophore (dibenzo-18-crown-6) to facilitate the transfer of protonated dopamine across the interface has been reported. ${ }^{9}$ The ITIES has also been used to investigate the transfer of highly hydrophilic ions. ${ }^{10}$ In our previous study, the transfer of heavy metal ions facilitated by di-

żE-mail: mvmiguel@hotmail.com; miguel_velazquez@uadec.edu.mx azadibenzo crown ethers and the carboxylic polyether "lasalocid A" has been carried out at the water|1,2-dichloroethane interface. ${ }^{11,12}$

The physicochemical parameters, such as partition equilibrium, are important to explain the hydrophobicity, which determines the chemical compound distribution between the aquatic and organic phases. In fact, acidic conditions are fundamental to the partition distribution of ionizable organic compounds. ${ }^{13}$

The mechanism of drug transfer across the ITIES has been studied. ${ }^{13}$ These studies have focused on the effect of $\mathrm{pH}$ and potential on the transfer of organic compounds across the ITIES. In fact, the ITIES has been used to explain the transfer process of molecules of environmental interest, such as triazine herbicides. ${ }^{14}$ Yudi's group was the first to investigate the transfer of a series of triazine herbicides at the ITIES. This work was focused on analytical applications. ${ }^{15-17}$ Recent studies have employed partition ionic diagrams (PID) to understand the phenomenon of drug partition and to represent the solubility profiles as a function of $\mathrm{pH}$ and interfacial potential. ${ }^{18-22}$

PID representing the transfer of organic molecules can be developed from parameters obtained by cyclic voltammetry or square wave voltammetry experiments performed at different $\mathrm{pH}$ values to determine the transfer potential as a function of $\mathrm{pH}$. The PID could be used as a tool to explain the behavior of some xenobiotics in the environment, especially of those in contact with biological membranes. The aim of this work is to study the electrochemical behavior of the SIM herbicide at the water|1,2-dichloethane interface.

\section{Experimental}

The $\mathrm{p} K_{\mathrm{a}}$ determination of SIM was spectrophotometrically carried out using a UV-Vis spectrophotometer (Cary 300, Agilent Technologies). The spectral data were processed with the WinUV Color software (Agilent Technologies). A solution of $0.14 \mathrm{mM}$ SIM was prepared using $2 \% \mathrm{~V} / \mathrm{V}$ water-methanol. The $\mathrm{pH}$ of the SIM solution was modified by the addition of $\mathrm{HCl}$. Finally, the $\mathrm{pH}$ value was monitored with a potentiometer (ThermoOrion Scientific, USA) and a combined $\mathrm{pH}$ electrode.

For the electrochemical experiments, a four-electrode cell with an area of $0.2 \mathrm{~cm}^{2}$ was employed. 1,2-Dichloroethane (1,2-DCE, Sigma-Aldrich) was used as the organic phase. Tetraphenylarsonium tetrakis(4-chlorophenyl)borate (TPAsTPBCl) and $\mathrm{LiCl}$ (Sigma-Aldrich) were used as supporting electrolytes in the organic 
<smiles>CCNc1nc(S)nc(NCO)n1</smiles>

Figure 1. Chemical structure of SIM.

and aqueous phases, respectively. TPAsTPBCl was prepared from tetraphenylarsonium chloride (TPAsCl, Fluka), and potassium tetrakis(4-chlorophenyl)borate (KTPBCl, Fluka purum). TPAsTP$\mathrm{BCl}$ was precipitated and re-crystallized twice from acetone (J. T. Baker). SIM was obtained from Sigma-Aldrich and used as received (Figure 1). $\mathrm{pH}$ was adjusted with $\mathrm{H}_{2} \mathrm{SO}_{4}$ or $\mathrm{LiOH}$ (SigmaAldrich). The aqueous solutions were prepared using deionized water. The polarization of the ITIES was carried out with a potentiostat/galvanostat (Gamry, Reference-600, USA). All experiments were performed at room temperature $\left(25^{\circ} \mathrm{C}\right)$ and a Faraday cage was used.

\section{Results and Discussion}

Spectrophotometric determination of the $\mathrm{p} K_{a}$ of SIM.-Figure 2 shows the absorption spectrum of SIM in the aqueous phase. The two peaks at $223 \mathrm{~nm}$ in the UV region are attributable to the basic species. The absorption maximum suffers a hypochromic effect.

The peak at $254 \mathrm{~nm}$ corresponds to the acidic species; however, when $\mathrm{pH}$ increases, a hypochromic effect is observed. As the solution becomes more acidic, an isosbestic point appears at $246 \mathrm{~nm}$, proving that this molecule shows a basic equilibrium with $\mathrm{p} K_{\mathrm{a}}$ in between.

On the other side, Figure 3 shows the absorbance values obtained at two wavelengths $(223 \mathrm{~nm}$ and $260 \mathrm{~nm})$ as a function of $\mathrm{pH}$. These wavelengths show two absorption values, where each one corresponds to the neutral and protonated species. When the concentration of both species is equal, the absorbance corresponds to half of the maximum absorption. The calculated $\mathrm{p} K_{\mathrm{a}}$ value is 3.88 .

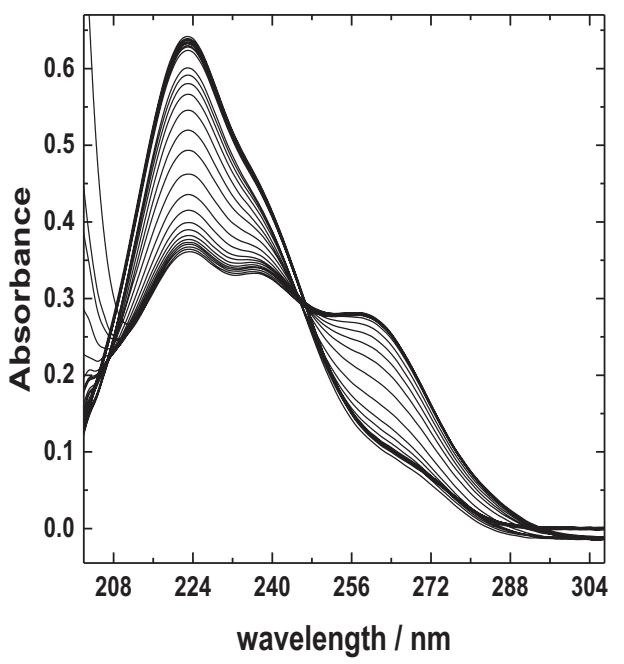

Figure 2. Absorption spectra for SIM $(0.14 \mathrm{mM})$ as a function of $\mathrm{pH}$.

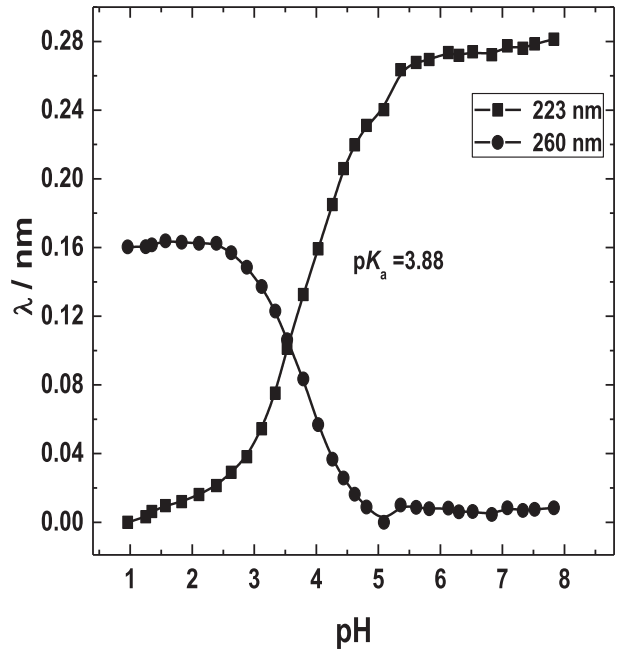

Figure 3. Determination of $\mathrm{p} K_{\mathrm{a}}$ for SIM.

Cyclic voltammetry.-Figure 4 shows a cyclic voltammogram of the SIM transfer at the water|1,2-DCE interface. The baseline (dotted line) corresponds to the signal of the supporting electrolyte. The cell employed can be summarized as follows:

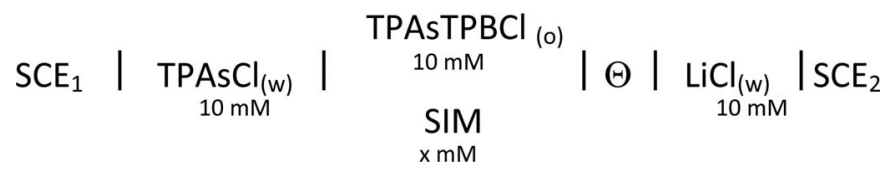

where $x \mathrm{mM}$ is the SIM concentration in the organic phase; $\Theta$ represents the interface being studied, and $\mathrm{SCE}_{1}$ and $\mathrm{SCE}_{2}$ are saturated calomel electrodes.

The potentials were reported on the Galvani potential scale and calculated according to: ${ }^{23}$

$$
E_{C E L L}=\Delta_{o}^{w} \phi-\Delta_{o}^{w} \phi_{T P A s^{+}}
$$

where $\Delta_{o}^{w} \phi$ is the Galvani interfacial potential and $\Delta_{o}^{w} \phi_{T P A s^{+}}$is the organic reference liquid junction potential. ${ }^{24}$ The standard transfer potential of TPAs ${ }^{+}, \Delta_{o}^{w} \phi_{T P A s^{+}}^{o}$, was considered as $-0.364 \mathrm{~V}^{25}$

At both ends of the potential window, the cations and anions of the supporting electrolyte are transferring across the interface. Thus, the organic cations $\mathrm{TPBCl}^{-}$and $\mathrm{TPAs}^{+}$limit the potential window.

When SIM is injected into the organic phase and the electric polarization is carried out in the positive potential direction, a positive current peak is observed at $0.065 \mathrm{~V}(\mathrm{pH}=2.03)$. This means that $\mathrm{SIMH}^{+}$is being transferred to the organic phase, as the current wave is clearly different from the baseline. As soon as the polarization scan rate back, a current peak appears at $-0.003 \mathrm{~V}$. The positive and negative currents are symmetric and show a single charge transfer across the interface because the average peak-to-peak separation was $65 \mathrm{mV}$, which is close to the theoretical value given by the Nernst equation $(59 \mathrm{mV})$ for a single charge transfer. Under these two criteria, it is possible to say that SIM transfer is a reversible process because this molecule has a single ionizable group with $\mathrm{p} K_{\mathrm{a}}=$ 3.8 , as shown previously. The transfer mechanism of SIM follows the equilibrium (2) because the $\mathrm{pH}$ of the aqueous phase is equal to 2.03 .

$$
\mathrm{SIM}_{(\text {or })} \rightleftarrows \mathrm{SIM}_{(\mathrm{w})}+\mathrm{H}^{+}{ }_{(\mathrm{w})} \rightleftarrows \mathrm{SIMH}^{+}{ }_{(\mathrm{w})} \rightleftarrows \mathrm{SIMH}^{+} \text {(or) }
$$

where $\mathrm{A}_{(\text {or })}$ and $\mathrm{A}_{(\mathrm{w})}$ are the neutral molecule in the organic and aqueous phases, respectively; $\mathrm{AH}^{+}{ }_{(\text {or) }}$ and $\mathrm{AH}^{+}$(or) are the protonated molecule in the organic and aqueous phases, respectively. 

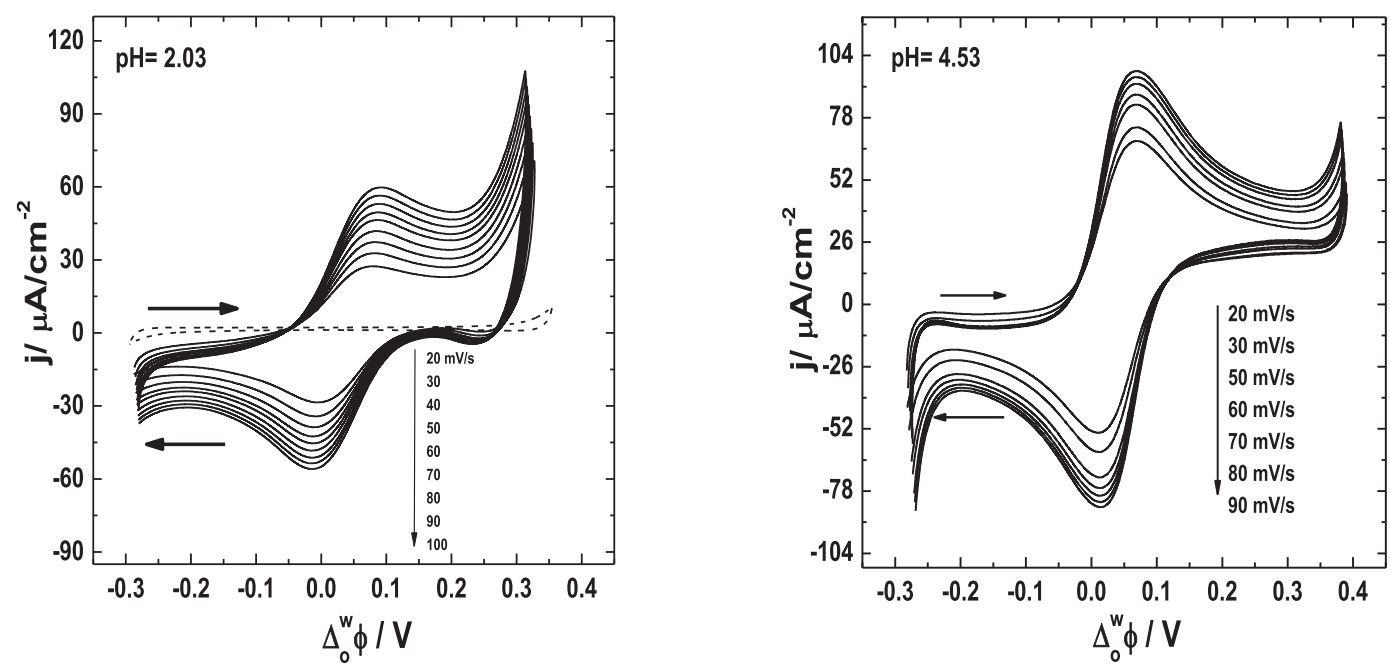

Figure 4. Cyclic voltammogram for the transfer of SIM $(0.1 \mathrm{mM})$ at the water|1,2-DCE interface at different pH values (2.03 and 4.53). Supporting electrolyte: TPAsTPBCl $0.01 \mathrm{M}$ in the organic phase and $\mathrm{LiCl} 0.01 \mathrm{M}$ in the aqueous phase.

On the other hand, the current peak remains at the same potential when the scan rate was changed (Figure 5). Because it showed a linear behavior, the Randles-Sevcik analysis of the current peak may be performed according to: ${ }^{26}$

$$
\mathrm{I}_{\mathrm{pc}}=\left(2.69 \times 10^{5}\right) \mathrm{n}^{3 / 2} \mathrm{~A} c \mathrm{D}^{1 / 2} \mathrm{v}^{1 / 2}
$$

where $\mathrm{i}_{\mathrm{pc}}$ is the peak current; $\mathrm{A}$ is the contact area between the two liquids; $c$ is the concentration of the herbicide; $\mathrm{D}$ is the diffusion constant; $\nu$ is the scan rate; and $n$ is the number of charges transferring across the interface. From this analysis, the diffusion coefficient $\left(D_{S I M H^{+}}^{w}\right)$ was evaluated to be $1.34 \times 10^{-5} \mathrm{~cm}^{2} \mathrm{~s}^{-1}$ for the aqueous phase. This value is comparable to that of similar compounds. ${ }^{14}$ The ratio $\mathrm{D}^{\circ} / \mathrm{D}^{\mathrm{w}}$ was evaluated from Walden's rule $\mathrm{D}^{\mathrm{o}} / \mathrm{D}^{\mathrm{w}}=\eta^{\mathrm{w}} / \eta^{\mathrm{o}}$, where $\eta^{\circ}$ and $\eta^{\mathrm{w}}$ are the viscosity coefficients of the organic solvent and water, respectively. Thus, the ratio $\mathrm{D}^{\mathrm{o}} / \mathrm{D}^{\mathrm{w}}$ is 1.01 , and $D_{S I M H^{+}}^{o}=1.36 \times 10^{-5} \mathrm{~cm}^{2} \mathrm{~s}^{-1}$ is the diffusion coefficient in the organic phase.

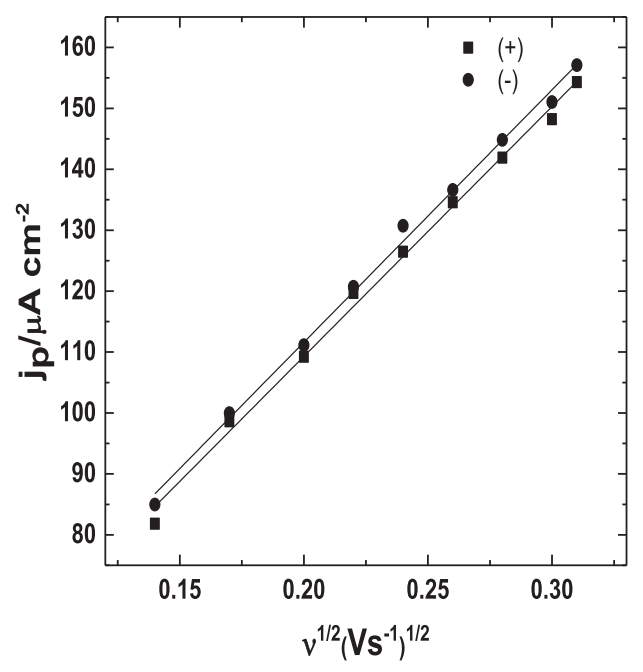

Figure 5. Peak current dependence on the square root of the sweep rate for SIM transfer at the water|1,2-DCE interface. The experimental condition was at $\mathrm{pH} \mathrm{2.03;(+)} \mathrm{and} \mathrm{(-)} \mathrm{are} \mathrm{the} \mathrm{positive} \mathrm{and} \mathrm{negative} \mathrm{peak}$ currents.
Ionic diagram.-Figure 6 shows the ionic partition diagram for the herbicide SIM at the water|1,2-DCE interface. This behavior can be explained as follows. When $\mathrm{pH}<\mathrm{p} K_{\mathrm{a}}$ of SIM, the transfer of this compound is dominated by the whole protonated form of SIM $\left(\mathrm{SIMH}^{+}\right)$. Thus $\Delta_{o}^{w}=\Delta_{o}^{w} \phi_{S I M H^{+}}^{0^{\prime}}$ (formal transfer potential for SIM) and the value of $\Delta_{o}^{w} \phi_{S I M H^{+}}^{0^{\prime}}=0.038 \mathrm{~V}$. At this point the potential is not $\mathrm{pH}$-dependent. When $\mathrm{pH}>\mathrm{p} K_{\mathrm{a}}$, the potential is dependent on the $\mathrm{pH}$, and the slope is equal to $60 \mathrm{mV}$. In this case, SIM acts as a proton carrier across the interface. This means that the herbicide does not pass into the aqueous phase; in fact, the protonation takes place at the interface. ${ }^{13}$ Thus, the reaction takes places at the interface and the $\mathrm{pH}$-potential plot will correspond to a slope different to zero. The reaction mechanism can be summarized as follows:

$$
\mathrm{SIM}_{(\mathrm{or})}+\mathrm{H}^{+}{ }_{(\mathrm{w})} \rightleftarrows \mathrm{SIMH}^{+} \text {(or) }
$$

The intersection between the two lines, corresponding to $\mathrm{pH} \approx 3.8$, agrees with the $\mathrm{p} K_{\mathrm{a}}$ obtained by spectrophotometric measurements. From an environmental point of view, this type of diagram could help

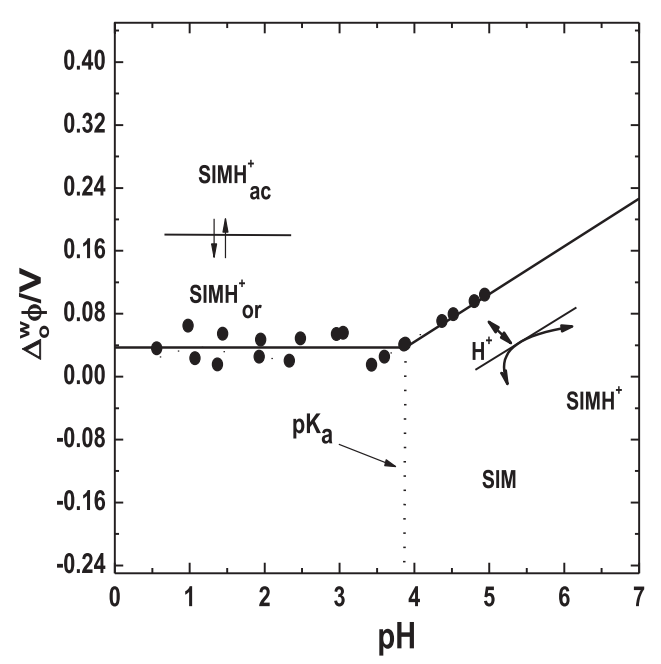

Figure 6. Ionic partition diagram for the SIM herbicide. The symbols represent the experimental data and the solid line corresponds to the theoretical fitting. 


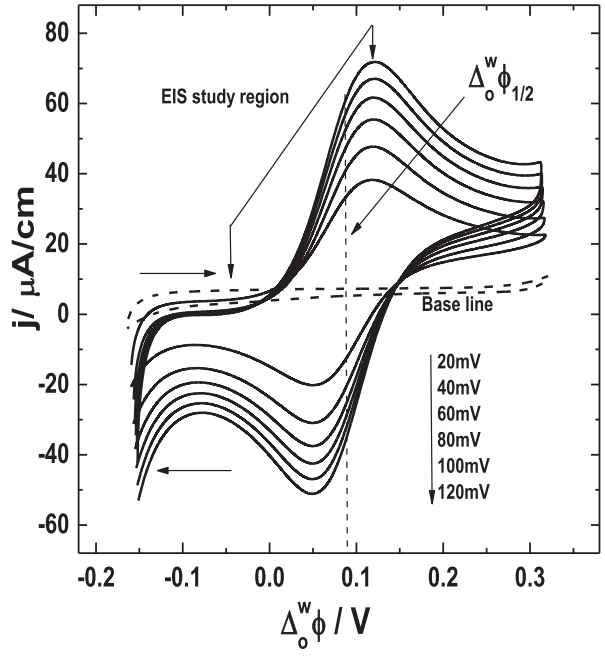

Figure 7. Cyclic voltammogram for the transfer of SIM $(0.1 \mathrm{mM})$ at the water|1,2-DCE interface. Supporting electrolyte: TPAsTPBCl $0.02 \mathrm{mM}$ in the organic phase and $\mathrm{LiCl} 0.02 \mathrm{M}$ in the aqueous phase.

to understand the partition equilibrium of organic molecules that can be harmful to living systems.

From the electrochemical experiments, it is possible to obtain the ionic partition coefficient $\left(\log P_{S I M H^{+}}^{0^{\prime}}\right)$ for $\mathrm{SIMH}^{+}$in a biphasic system (water|1,2-DCE interface). ${ }^{13}$ The $\Delta_{o}^{w} \phi_{S I M H^{+}}^{0^{\prime}}$ can be related to the transfer Gibbs energy $\left(\Delta_{o}^{w} G_{S I M H^{+}}^{0^{\prime \prime w \rightarrow o}}\right.$ ) from water to the organic phase.

$$
\Delta_{o}^{w} G_{S I M H^{+}}^{0^{\prime} w \rightarrow o}=z F \Delta_{o}^{w} \phi_{S I M H^{+}}^{0^{\prime}}
$$

where $\mathrm{z}$ is the charge and $\mathrm{F}$ is the Faraday constant. Thus, $\Delta_{o}^{w} G_{S I M H^{+}}^{0^{\prime} w \rightarrow o}$ can be calculated. Therefore, $\log P_{S I M H^{+}}^{0^{\prime}}$ can be evaluated:

$$
\log P_{S I M H^{+}}^{0^{\prime}}=\frac{\Delta_{o}^{w} G_{S I M H}^{0^{\prime} w \rightarrow o}}{2.3 R T}
$$

The values of $\Delta_{o}^{w} G_{S I M H^{+}}^{0^{\prime} w \rightarrow o}=3.57 \mathrm{~kJ} \mathrm{~mol}^{-1}$ and $\log P_{S I M H^{+}}^{0^{\prime}}=$ -0.622 were calculated. The physical interpretation is that the $\Delta_{o}^{w} G_{S I M H^{+}}^{0^{\prime} w \rightarrow o}$ is the amount of energy required for SIM to be transferred from the aqueous to the organic phase. Because $\log P_{S I M H^{+}}^{0^{\prime}}$, which represents the affinity of the herbicide to water, is the smaller value, SIM shows a higher affinity for the organic phase.

Impedance studies.-Figure 7 shows a cyclic voltammetry experiment for the transfer of SIM at the water|1,2-DCE interface. The cell employed is as follows:

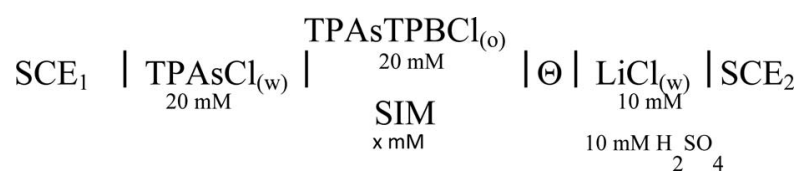

As shown above, the concentration of the supporting electrolyte was twice that used for the previous experiments. This helps to reduce the IR drop due to the presence of an organic solvent, thereby aiding the performance of electrochemical impedance spectroscopy (EIS). The higher supporting electrolyte concentration does not affect the electrochemical behavior of SIM, because the cations of the supporting electrolyte cross the interface at the edge of the potential windows. The EIS experiments were carried out at the potential region shown in Figure 7, which is basically the potential region where $\mathrm{SIMH}^{+}$ is transferred from the water to the organic phase (positive current peak).

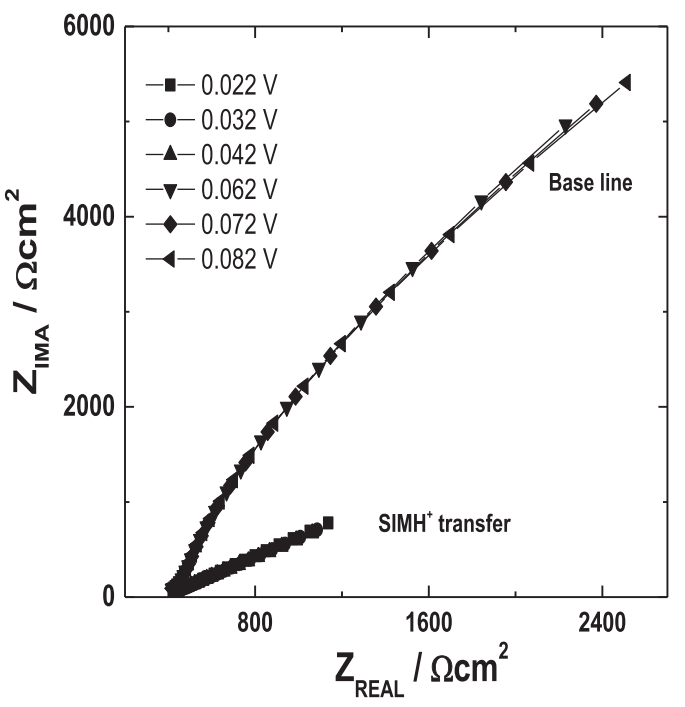

Figure 8. Nyquist plot for the transfer of $\mathrm{SIMH}^{+}$at the water|1,2-DCE interface for various applied potentials.

Figure 8 shows the Nyquist plot for the transfer of $\mathrm{SIMH}^{+}$at the liquid-liquid interface. The experiment was carried out between $200 \mathrm{~Hz}$ to $1.0 \mathrm{~Hz}$. The spectra for the base electrolyte show high impedance that is independent of the applied potential. The explanation is that the interface was polarized and no faradaic reaction took place, at least in the potential region shown in Figure 7. When SIM is injected into the organic phase, the resistance decreases due to the transfer of $\mathrm{SIMH}^{+}$across the interface, meaning that a faradaic reaction is taking place.

The impedance data were fitted to a simple Randles electric equivalent circuit, ${ }^{26}$ inset in Figure 9. The double layer capacitance $\mathrm{C}_{\mathrm{dl}}$, the solution resistance (Rs) and Warburg coefficient $(\mathrm{W})$ parameters were obtained and fitting error was Rs $(2.49 \%), \mathrm{W}(1.47 \%)$ and $\mathrm{C}_{\mathrm{dl}}(11 \%)$. As shown, the calculated double layer capacitance for the transfer of $\mathrm{SIMH}^{+}$across the interface drops at the half-wave potential for the transfer of $\mathrm{SIMH}^{+}$. The explanation for this process is that the faradaic reaction breaks the charge organization at the vicinity of the interface, and consequently, the charge is not stored at this point.

Moreover, the kinetic parameters can be extracted from the impedance experiments. The charge transfer resistance $\left(\mathrm{R}_{\mathrm{ct}}\right)$ can be useful for the calculation of the apparent rate transfer kinetics of $\mathrm{SIMH}^{+}\left(k_{a p}^{w \rightarrow o}\right)$ from water to the organic phase. The Rct was

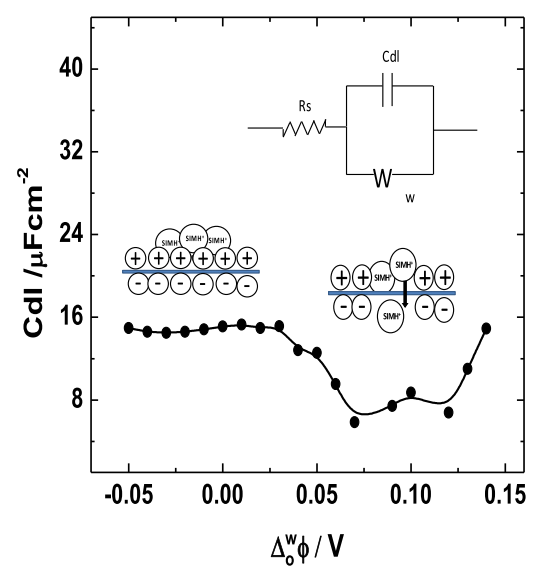

Figure 9. Double layer capacitance for the transfer of $\mathrm{SIMH}^{+}$at the water|1,2DCE interface. 


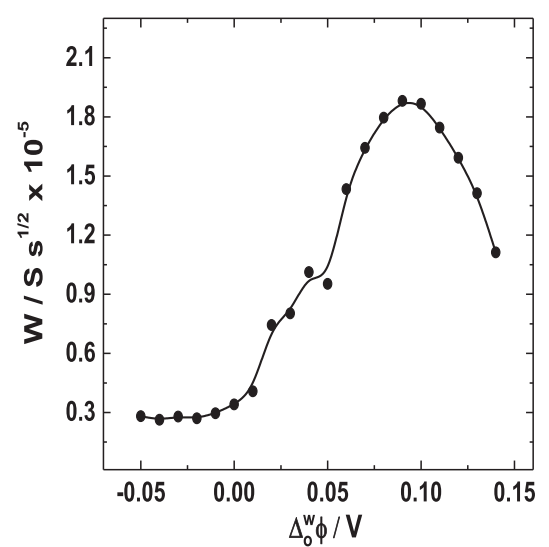

Figure 10. Warburg parameter as a function of the applied Galvani potential for the transfer of $\mathrm{SIMH}^{+}$at the water |1,2-DCE interface.

obtained plotting the real impedance $\left(\mathrm{Z}_{\mathrm{s}}\right)$ on the function of the angular frequency $(\omega)$ as is shown by the following equation:

$$
\mathrm{Z}_{\mathrm{s}}=\mathrm{R}_{\mathrm{ct}}+\sigma \omega^{-1 / 2}
$$

the $\omega=2 \pi f, f=$ frequency in $\mathrm{Hz}$ and $\sigma$ the mass transfer impedance component, the so-called Warburg coefficient.

Additionally, the $k_{a p}^{w \rightarrow o}$ was calculated using the Equation $8:{ }^{27}$

$$
R_{c t}=\frac{R T}{F^{2} A c k_{a p}^{w \rightarrow o}}
$$

where $\mathrm{A}$ is the contact area between the two liquids; $c$ is the concentration of SIM; $F$ is the Faraday constant; $\mathrm{R}$ the universal gas constant; and $\mathrm{T}$ is the absolute temperature. For instance, $k_{a p}^{w \rightarrow o}$ for the transfer of $\mathrm{SIMH}^{+}$(at the half-wave potential) was calculated to be 0.007 $\pm 0.001 \mathrm{~cm} \mathrm{~s}^{-1}$, and this value is in concordance with other values obtained for this type of system. ${ }^{28}$

The Warburg parameter is related to the diffusion of $\mathrm{SIMH}^{+}$in the aqueous phase across the interface. The data are interesting because the maximum values reached correspond to the half-wave potential (Figure 10), and the signal decreases considerably after that. This behavior is consistent with the results of the $\mathrm{CV}$ experiments and the current is dominated by the diffusion of $\mathrm{SIMH}^{+}$. Thus, the diffusion coefficient for the transfer of SIM can be calculated from the impedance data according to: ${ }^{29}$

$$
\sigma=\frac{R T}{\sqrt{2} z^{2} F^{2} A}\left(\frac{1}{\sqrt{D_{\text {SIMH }^{+}}^{o}} c^{o}}+\frac{1}{\sqrt{D_{\text {SIMH }^{+}}^{w}} c^{w}}\right)
$$

where $D_{\text {SIMH }^{+}}^{o}$ and $D_{\text {SIMH }^{+}}^{w}$ are the diffusion coefficients in the organic and aqueous phases, respectively; $c^{w}$ and $c^{o}$ are the concentrations of the herbicides in the aqueous and organic phases, respectively. However, under acidic conditions and at the half-wave potential, the concentration of the herbicide is considered to be $c^{w}=c^{o}$. For that $D_{\text {SIMH }^{+}}^{o}$ was $(1.34 \pm 0.6) \times 10^{-5}$; this value is close to that obtained by cyclic voltammetry experiments.

The hydrodynamic radius $\left(\mathrm{r}_{\mathrm{h}}\right)$ of $\mathrm{SIMH}^{+}$was calculated from the Stokes-Einstein equation ${ }^{30}$ using the diffusion coefficient in the organic phase:

$$
D_{S I M H^{+}}^{o}=k T / 6 \pi \eta r_{h}
$$

where $k$ is the Boltzmann constant and $\eta$ is the viscosity of the solvent. For 1,2-DCE, $\eta=0.779 \times 10^{-3} \mathrm{~Pa} . \mathrm{s}$ and, therefore, $\mathrm{r}_{\mathrm{SIMH}+}=0.21 \mathrm{~nm}$. This value is consistent with the dimension of this type of molecule. ${ }^{28}$

\section{Conclusions}

The present work shows how the ITIES can be an important tool in the study of the partitioning of environmentally important organic compounds, such as the herbicide SIM. Techniques such as cyclic voltammetry and EIS were successfully performed to the investigate of charge transfer at the liquid|liquid interface.

\section{Acknowledgments}

The authors are grateful for the support by the Secretaría de Educación Pública (SEP) project (UACOAH-PTC-359). HGM thanks CONACyT for the scholarship grant for postgraduate studies.

\section{ORCID}

Miguel Velázquez-Manzanares (10)

https://orcid.org/0000-0002-5125-1040

\section{References}

1. T. Narushima, T. Sato, Y. Goto, and Y. Takahashi, Water Air Soil Pollut, 225, 2229 (2014).

2. J. Stenersen, Chemical pesticides: Mode of Action and Toxicology, CRC Press (2004) Florida, USA.

3. J. Koryta, P Vanysek, and M. Brezina, J. Electroanal. Chem. Interfacial Electrochem., 67, 263 (1976).

4. C. J. Collins, C. Lyons, J. Strutwolf, and D. W. M. Arrigan, Talanta, 80, 1993 (2010).

5. C. J. Collins, A. Berduque, and D. W. Arrigan, Anal. Chem., 80(21), 8102 (2008).

6. S. O'Sullivan and D. W. M. Arrigan, Electrochim. Acta, 77, 71(2012).

7. P. D. Beattie, A. Delay, and H. H. Girault, J. Electroanal. Chem., 380, 167 (1995).

8. G. Herzog and V. Beni, Anal. Chim. Acta, 769, 10 (2013).

9. V. Benia, M. A. Ghita, and D. W. M. Arrigan, Biosens. Bioelectron., 20, 2097 (2005).

10. M. Zhou, S. Gan, L. Zhong, B. Su, and L. Niu, Anal. Chem., 82, 7857 (2010).

11. G. Guerrero-Trejo, J. C. Aguilar, J. Amador-Hernández, and M. Velázquez-Manzanares, J. Electrochem. Soc., 157(10), F144 (2010).

12. F. H. Barrera Cruz, J. Amador-Hernández, and M. Velázquez-Manzanares, J. Electrochem. Soc., 159(11), H893 (2012).

13. F. Reymond, V. Chopineaux-Courtois, G. Steyaert, G. Bouchard, P. A. Carrupt, B. Testa, and H. H. Girault, J. Electroanal. Chem., 462, 235 (1999).

14. M. Velázquez-Manzanares, J. Amador-Hernández, C. Cisneros-Cisneros, and K. A. Heredia-Lezama, J. Electrochem. Soc., 155(10), F218 (2008).

15. A. V. Juarez, J. S. Riva, and L. M. Yudi, in Herbicides and Environment, A. Kortekamp, Editor p. 231, InTec, India (2011).

16. A. V. Juarez and L. M. Yudi, Electroanalysis, 21(6), 767 (2009).

17. A. V. Juarez and L. M. Yudi, Electroanalysis, 15(18), 1481 (2003).

18. V. Gobry, G. Bouchard, F. Reymond, P. A. Carrupt, B. Testa, and H. H. Girault, Helv. Chim. Acta, 83, 1465 (2000).

19. F. Reymond, P. A. Carrupt, B. Testa, and H. H. Girault, Chemistry-A European J., 5, 39 (1999).

20. F. Reymond, G. Steyaert, A. Pagliara, P-A. Carrupt, B. Testa, and H. H. Girault, Helv. Chim. Acta, 79, 1651 (1996).

21. F. Reymond, G. Steyaert, A. Pagliara, P. A. Carrupt, B. Testa, and H. H. Girault, Helv. Chim. Acta, 79, 101 (1996)

22. F. Reymond, G. Steyaert, P. A. Carrupt, B. Testa, and H. H. Girault, J. Am. Chem. Soc., 118, 11951 (1996).

23. M. C. Wiles, T. J. VanderNoot, and D. J. Schiffrin, J. Electroanal. Chem., 281, 231 (1990).

24. V. J. Cunnane, D. J. Schiffrin, C. Beltran, G. Geblewicz, and T. Solomon, J. Electroanal. Chem., 247, 203 (1988).

25. J. Koryta, P. Vanysek, and M. Brezina, J. Electroanal. Chem., 75, 211 (1977).

26. A. J. Bard and L. R. Faulkner, Electrochemical methods: fundamentals and Applications, p. 218, John Wiley \& Sons., New York, (1980). E. P. Able and A. T. Baker, Diamond Films, p. 37, John Wiley\& Sons, New York (1991).

27. H. A. Santos, C. M. Pereira, and F. Silva, Port. Electrochim. Acta, 22, 263 (2005).

28. M. Velázquez-Manzanares, J. Amador-Hernández, I. M. de la Garza Rodríguez, E. M. Colunga Urbina, and F. Canseco Sánchez, Int. J. Electrochem. Sci., 11, 2927 (2016).

29. Y. Cheng and D. J. Schiffrin, J. Chem. Soc. Faraday Trans., 89(2), 199 (1993)

30. C. M. A. Brett and A. M. Oliveira Brett, Electrochemistry: Principle, methods, and applications, p. 29, Oxford University Press New York, (2002). 